\title{
Estimating the impact of implementation and timing of COVID-19 vaccination program in Brazil: a counterfactual analysis
}

\author{
Leonardo Souto Ferreira ${ }^{1,2,}$, Flávia Maria Darcie Marquitti ${ }^{2,3}$, Rafael Lopes Paixão da Silva ${ }^{1,2}$, \\ Marcelo Eduardo Borges ${ }^{2}$, Marcelo F C Gomes ${ }^{4,2}$, Oswaldo G Cruz ${ }^{4,2}$, Roberto André Kraenkel ${ }^{1,2}$, \\ Renato Mendes Coutinho ${ }^{2,5}$, Paulo Inácio Prado ${ }^{2,6}$, and Leonardo S Bastos ${ }^{4,2}$ \\ ${ }^{1}$ Instituto de Física Teórica, Universidade Estadual Paulista, São Paulo, Brazil \\ ${ }^{2}$ Observatório COVID-19 BR \\ ${ }^{3}$ Instituto de Física 'Gleb Wataghin' and Instituto de Biologia, Universidade Estadual de Campinas, \\ Campinas, Brazil \\ ${ }^{4}$ Fundação Oswaldo Cruz, Programa de Computação Científica, Grupo de Métodos Analíticos em Vigilância \\ Epidemiológica, Rio de Janeiro, Brazil \\ ${ }^{5}$ Centro de Matemática, Computação e Cognição, Universidade Federal do ABC, Santo André, Brazil \\ ${ }^{6}$ Instituto de Biociências, Universidade de São Paulo, São Paulo, Brazil \\ *Corresponding author: leonardo.souto@unesp.br
}

December 24, 2021

\begin{abstract}
The vaccines developed in 2020-2021 against the SARS-CoV-2 virus were designed to prevent severity and deaths due to COVID-19. However, how effective this vaccination campaign was at saving lives remains a methodological challenge. In this work, we developed a Bayesian statistical model to estimate the number of deaths and hospitalizations in individuals above 60 years old in Brazil. Using the actual number of hospitalized and deaths from the Brazilian database, and also the coverage of second dose according to the National Immunization Program, we rebuilt the realized scenario as well as the hypothetical scenario without vaccination in Brazil in order to perform a counterfactual analysis. By computing the difference between the hypothetical and realized scenarios, we were able to estimate the direct effect of COVID-19 vaccination in Brazil. We also evaluated two other hypothetical, but not impossible, scenarios considering earlier vaccination roll-outs. We estimated that more than 165 thousand of $60+$ years old individuals were not hospitalized due to COVID-19 until August 28, 2021, and other approximately 100 thousand individuals could not have been hospitalized if the immunization started as soon it was approved in Brazil. We also estimate that more than 75 thousand lives were saved in the period analysed for the same age group, and additional 48 thousand lives could have been saved if the Brazilian Government started the immunization 8 weeks earlier.
\end{abstract}

\section{Introduction}

Since March 15 2020, SARS-CoV-2 has been declared in community transmission in Brazil, by the Ministry of Health. During the first vear of the pandemic the epidemic spread fast in Brazil but with different timings and burdens between regions, because of regional differences in health assistance, income and local mitigation policies. On top of that, by January of 2021, 
medRxiv preprint doi: https://doi.org/10.1101/2021.12.24.21268384; this version posted December 27, 2021. The copyright holder for this preprint (which was not certified by peer review) is the author/funder, who has granted medRxiv a license to display the preprint in

It is made available under a CC-BY-ND 4.0 International license .

Brazil's epidemics saw a strong increase in the number of notified cases and deaths due to SARS-CoV-2, specially in the northern region of Brazil [2]. The new burst quickly spread to the rest of the country, synchronizing the waves in each region, reducing by the end of May. This wave was later associated with the appearance of the VOC P.1, also known as Gamma, whose origin was identified as November of 2020, in Manaus [20, 26]. Brazil also had community transmission of Alpha VOC, however, it was not capable of overcoming Gamma, because the later was found more transmissible and with a potential immunity escape [3, 21, 26]. Gamma variant was eventually substituted by the Delta variant in frequency, although the majority of Brazilian COVID-19 cases and deaths in 2021 were during the Gamma dominance [7]. The country did not suffer, so far, another marked increase in cases and deaths as other countries and such difference is attributed to the vaccination campaign in Brazil.

Brazil has an outstanding history of successful government policies for mass vaccination, which include coordinated vaccination campaigns at country level, effective communication strategies, free availability of doses and the capillarity of the Brazilian's Unified Health System (SUS). For instance, in 2010, the SUS was able to vaccinate 89 millions of individuals [4] in response to the $2009 \mathrm{H} 1 \mathrm{~N} 1$ influenza pandemic. However, due to several cuts in fundings to SUS and widespread misinformation, the later vaccination campaigns were not able to fulfill the coverage objectives [22]. The COVID-19 vaccination campaign in Brazil suffered with a poor coordination and logistic at the federal level [6], which delayed and slowed down the pace of vaccine rollout. Vaccination eventually started in January 17, 2021, first covering institutionalized and indigenous individuals, and health professionals. After that, the vaccination rollout was structured considering age groups, from older to younger individuals, in a at-risk basis [18, 11]. Currently, Brazil has $88.9 \%$ of the adult population and $66.7 \%$ of the total population with one and two doses by the date of December 22, 2021 [17], with an ongoing campaign of booster inoculation, a coverage that surpass richer countries who had earlier availability of vaccines.

However, we still lack the information of how effective this vaccination campaign was in preventing hospitalizations and deaths countrywide, the main objective of the developed vaccines. The only estimates available are for Sao Oaulo State, the most populous State and higher GDP in Brazil [9]. Around 24 thousand hospitalizations and 11 thousand deaths averted by vaccination in São Paulo state in the age group of $65+$ between February 8 and May 28 of 2021, reducing hospitalization costs in US\$287 millions. Thus, our objective is to expand these results for the whole country, also accounting for other possible scenarios of vaccination rollout.

We developed an statistical model to predict the number of deaths and hospitalizations by COVID-19 in elderly age groups from the time series of deaths and cases in younger age groups. The model takes into account the reduction in relative risks of older age groups as vaccine coverage progressed in the elderly population over time. We then used the estimated effect of vaccine coverage on reducing relative risks in a counterfactual analysis to estimate the direct effect of vaccination in averting hospitalizations and deaths by COVID-19 in Brazil. Since the model directly accounts for vaccination, we were also able to provide estimates or potential number of hospitalizations and deaths averted if vaccines were available earlier to the population. The analysis was conducted considering the age group of $60+$ years old with a time series that goes until August 28, 2021.

\section{Methods}

We built a Bayesian statistical model to infer and predict the number of hospitalizations and deaths due to COVID-19 in age classes above 60 years as a linear function of number of hospitalizations and deaths in the age class 20-29 y.o. and of the vaccine coverage in each age class. First, we retrieved the number of hospitalizations and deaths due to COVID-19 initially notified as Severe Acute Respiratory Illness (SARI) in each age bracket from the Influenza's 
medRxiv preprint doi: https://doi.org/10.1101/2021.12.24.21268384; this version posted December 27, 2021. The copyright holder for this preprint (which was not certified by peer review) is the author/funder, who has granted medRxiv a license to display the preprint in

It is made available under a CC-BY-ND 4.0 International license.

Epidemiological Surveillance Information System (SIVEP-Gripe [19]). We also used the coverage of second dose (counting after 14 days from inoculation) of each vaccine $v=\{$ AZD1222, CoronaVac, BNT162b2\}, produced by AstraZeneca/Oxford/Fiocruz, Sinovac/Butantan and Pfizer/BioNTech, respectively, from the National Plan of Vaccination's Information Database (SI-PNI [17]). Besides these three vaccines, Ad26.COV2.S (Janssen) was also used in Brazilian territory, however, we considered that the number of inoculated doses was too low to have statistical significance in this analysis. The model is given by:

$$
\begin{aligned}
Y^{(t)} & \sim \operatorname{Normal}\left(\mu^{(t)}, \sigma\right), \quad \sigma>0, \quad t=1,2, \ldots \\
\mu^{(t)} & =\beta_{0}+\beta_{1} X^{(t)}+\sum_{v} \beta_{v} X^{(t)} \operatorname{cov}_{Y, v}^{(t)}+\gamma^{(t)}
\end{aligned}
$$

where $Y^{(t)}$ denotes the number of hospitalizations/deaths at time $t$ expected in the age bin being studied, $X^{(t)}$ the number of hospitalizations/deaths at time $t$ of the age bin being used as reference, $\operatorname{cov}_{i, v}^{(t)}$ denotes the coverage of vaccine $v$ in age bin $i$ at time $t$, and $\gamma^{(t)}$ for $t=1,2, \ldots$ are temporal Gaussian random effects, modelled as a first-order autoregressive process, AR(1), as the following

$$
\begin{aligned}
\gamma^{(t)} & \sim \operatorname{Normal}\left(\rho \gamma^{(t-1)}, \phi\right), \quad \phi>0, \quad|\rho|<1, \quad t=2,3 \ldots \\
\gamma^{(1)} & \sim \operatorname{Normal}\left(0,\left(\phi\left(1-\rho^{2}\right)\right)^{-1}\right),
\end{aligned}
$$

$\rho$ is a temporal correlation and $\phi$ is the random effects precision.

The model assumes a linear relationship between $Y$ and $X$ in absence of vaccination. The third term in equation 1 express that the difference between $X$ and $Y$ when vaccination is present is linearly related to the coverage of each vaccine (notice that a different $\beta$ is fitted to each vaccine). Finally, the latter term accounts for temporal dependence among hospitalizations/deaths (common in epidemiological modelling). Notice also that $\mu^{(t)}$ could be written compactly as:

$$
\mu^{(t)}=\beta_{0}+X^{(t)}\left(\beta_{1}+\sum_{v} \beta_{v} \operatorname{cov}_{Y, v}^{(t)}\right)+\gamma^{(t)}
$$

making explicit the role of vaccination in the model, but we stick to the first definition for the sake of understanding, and to improve convergence of the numerical method.

Finally, our prior distributions are given (in terms of precision) by:

$$
\begin{aligned}
p\left(\beta_{0}\right) & \propto 1, \\
\beta_{1} & \sim \operatorname{Normal}(0,0.001), \\
\beta_{v} & \sim \operatorname{Normal}(0,0.001), \\
\sigma & \sim \operatorname{Gamma}(1,0.00001),
\end{aligned}
$$

and the prior distributions of the $\mathrm{AR}(1)$ random effects (following the notation of [24]) are given by:

$$
\begin{aligned}
\kappa=\phi\left(1-\rho^{2}\right) & \sim \operatorname{Gamma}(2,100) \\
\theta=\log \left(\frac{1+\rho}{1-\rho}\right) & \sim \operatorname{Normal}(0,0.15) .
\end{aligned}
$$

The inference is done using the integrated nested Laplace approximation (INLA) approach [24] implemented in R [23] using R-INLA package [25] and was fitted independently for each target age group (here 60-69, 70-79 and 80+) and state using 20-29 as age group of reference ( $X$ variable) between March 1, 2020, and August 29, 2021. The posterior trajectories of fitted 
medRxiv preprint doi: https://doi.org/10.1101/2021.12.24.21268384; this version posted December 27, 2021. The copyright holder for this preprint (which was not certified by peer review) is the author/funder, who has granted medRxiv a license to display the preprint in

It is made available under a CC-BY-ND 4.0 International license .

and simulated time series were drawn from 1000 samples for each simulation set and added to generate an aggregated posterior sample to the whole of Brazil, also providing a 95\% Credible Interval (hereafter, $95 \% \mathrm{CI}$ ).

To estimate the effect of vaccination, we set the values of coverage to zero and predicted the number of hospitalizations/deaths expected in the absence of the explanatory variables of coverage. We then compare the cumulative number of hospitalizations/deaths of this hypothetical trajectory with their equivalent when vaccine coverage is considered from January 1, 2021 up to August 29, 2021. We also estimated the effect of vaccination on COVID-19 dynamics if vaccines were available earlier in 2021. We thus created two simple counterfactual scenarios of earlier vaccination but the same rollout by shifting the time series of observed vaccine coverage to begin 4 and 8 weeks earlier, for each age target age group. In these scenarios the coverage of the last 4 or 8 weeks was those observed in the following weeks in the true time series.

\section{Results}

The model provided an excellent fit to the all observed time series (orange lines and black points in Fig. 1, also see Fig. 1 in the Supplementary Material, hereafter SM), showing that the risk of hospitalizations and deaths in the target groups relative to the reference group were little affected during the first half of 2021, when vaccine coverage was still small. The good fit did not changed after this point, and thus the model is providing a realistic estimate of the reduction of relative risks of casualties in the target groups, as coverage increases (see Fig. 2 from SM).

By making this reduction equal to zero, we have projected the number of hospitalizations and deaths caused by COVID-19 until August 29, 2021 in the absence of vaccination (Fig. 1). We see that, whilst the vaccination was not able to suppress the wave of cases and deaths due to the Gamma variant (February-March 2021), it was decisive to preclude the following wave of the deaths and hospitalizations that at the time of the introduction of the Delta variant (MayJuly 2021). As expected, the counterfactual time series diverges from the observed time series earlier for the eldest age groups, which were vaccinated first. Therefore, the model estimates a decrease in deaths and hospitalizations that would be caused by the Delta VOC wave only for the $80+$ y.o. age group.

If the vaccination rollout started 4 weeks earlier, it would strongly reduce the number of hospitalizations and deaths due to COVID-19 in the 80+ age group, whereas 60-69 and 70-79 groups would also be considerably positively affected Fig. 2). When we consider an earlier vaccine deployment of 8 weeks, we see that the deaths and hospitalizations of the Gamma wave would be almost completely avoided in the $80+$ age group, with a marked reduction in the other age groups.

If we compare the cumulative number of hospitalizations and deaths between January 1, 2021, and August 29, 2021, with the counterfactual estimates, we estimate that vaccinating against COVID-19 directly accounts for reducing at least 166,780 (95\% CI: 157,198-176,309) hospitalizations and 76,503 (95\% CI: 71,832-80,714) deaths in the target age groups. These figures increase to 219,006 (95\% CI: 205,903-232,651) and 101,416 (95\% CI: 95,079-107,091), respectively, if we assume that the same vaccination rollout was done 4 weeks earlier. if the vaccination rollout had been done 8 weeks earlier, the number of hospitalizations and deaths averted would increase further to 268,614 (95\% CI: 248,858-289,034) and 124,962 (95\% CI: 116,573-132,234), respectively (Fig. 3 and Table 1). 

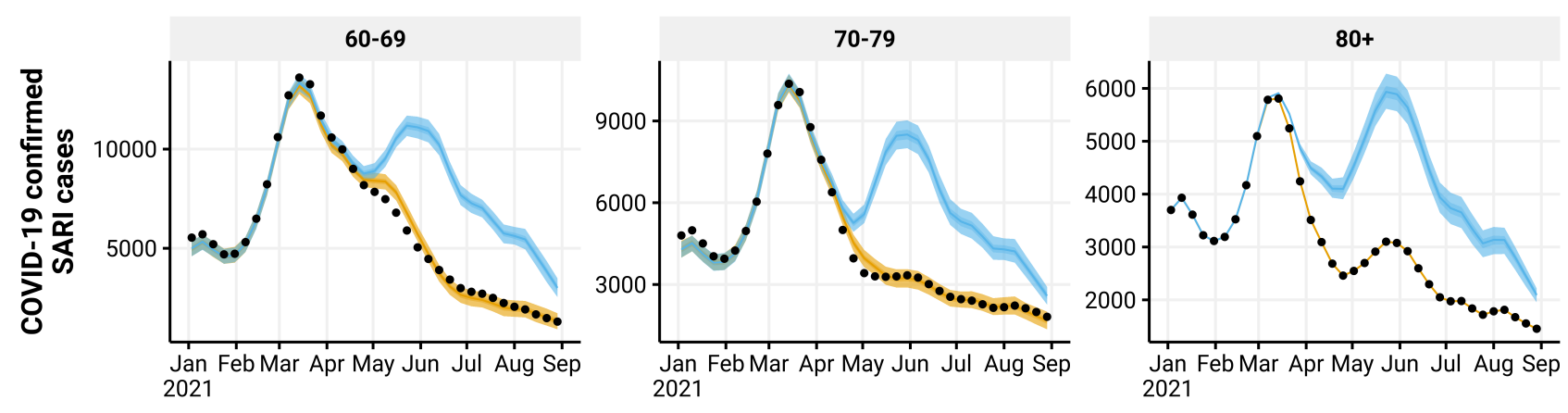

Epidemiological week of onset of symptoms
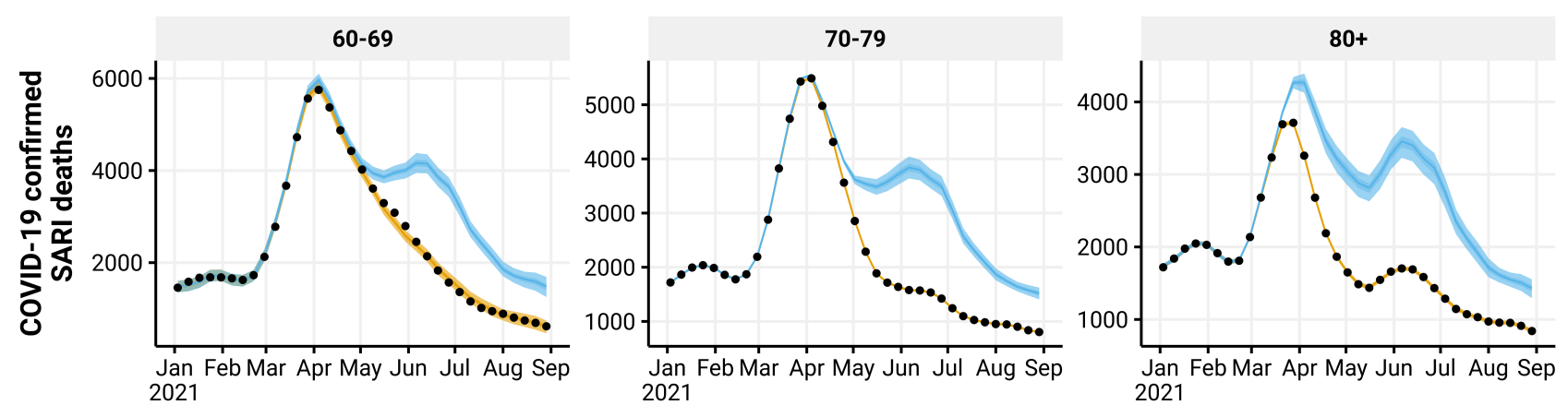

Epidemiological week of death

- Fitted model • Projection without vaccination

Figure 1: Estimated number of hospitalizations (top) and deaths (bottom) by epidemiological week with (orange) or without (blue) vaccination rollout, by age group (panels). The observed number of hospitalizations and deaths are given by the black points.

\section{Discussion}

In this work we used a Bayesian model approach to estimate the number of hospitalizations and deaths in the most vulnerable population to COVID-19 (60+ y.o.) in Brazil. We predicted accurately the decrease in the number of hospitalizations and deaths in the age groups more vulnerable to COVID-19 as a function of the increasing vaccine coverage in the first eight months of vaccination in Brazil. Such good fit was provided by assuming only that the risks relative to a reference group decreases as vaccination coverage increases in the target groups. Our additive model allowed to sort out the estimated effect of vaccination, and thus to simulate counterfactual scenarios of no vaccination (that is, constant relative risk) and also earlier vaccination rollout. Therefore, we are able to show the number of lives which were directly saved, and the amount that could have been saved if hypothetical, but not impossible, starting dates were accomplished in Brazil.

We highlight some points that we discuss in the next paragraphs: (i) we only considered direct effect of vaccination, therefore no herd immunity and no secondary morbidity or mortality effects were considered here; (ii) we performed analysis considering only the most vulnerable age population (60+ y.o.), which was responsible for the $42.5 \%$ of hospitalizations and $62.8 \%$ of deaths in Brazil during the period analysed; and (iii) we considered exactly the same pace of vaccination in our hypothetical scenarios that was realized, which is very small if compared to the speed capacity and organization Brazil had during previous vaccination rollouts. All the three points, alone and combined, allow us to affirm/state that our estimates are a lower bound for the saved lives in the most critical period of COVID-19 epidemics in Brazil.

Our estimates show that more than 165 thousands of individuals were not hospitalized due 

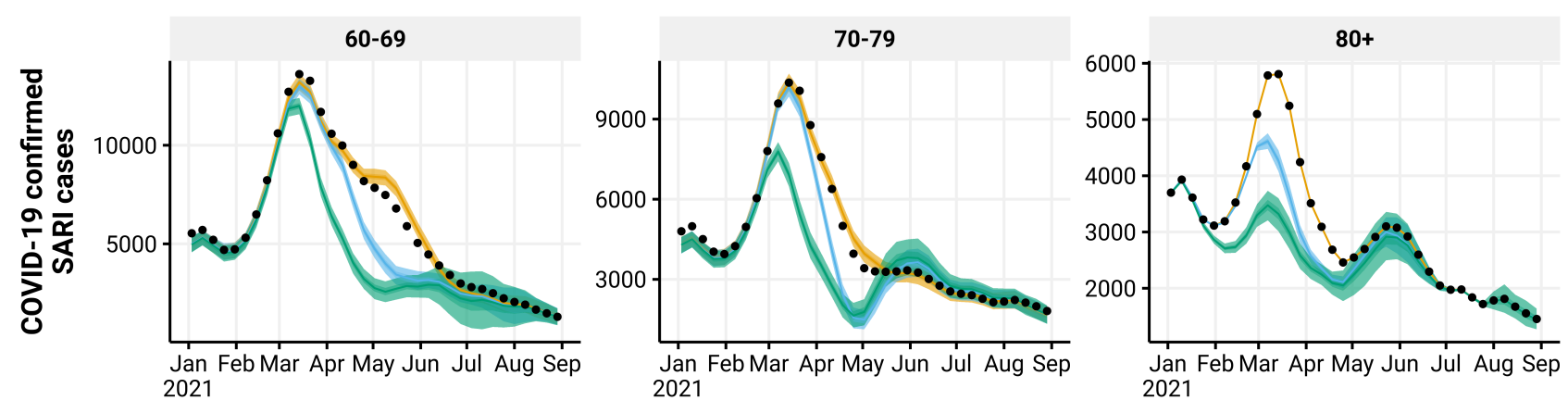

Epidemiological week of onset of symptoms
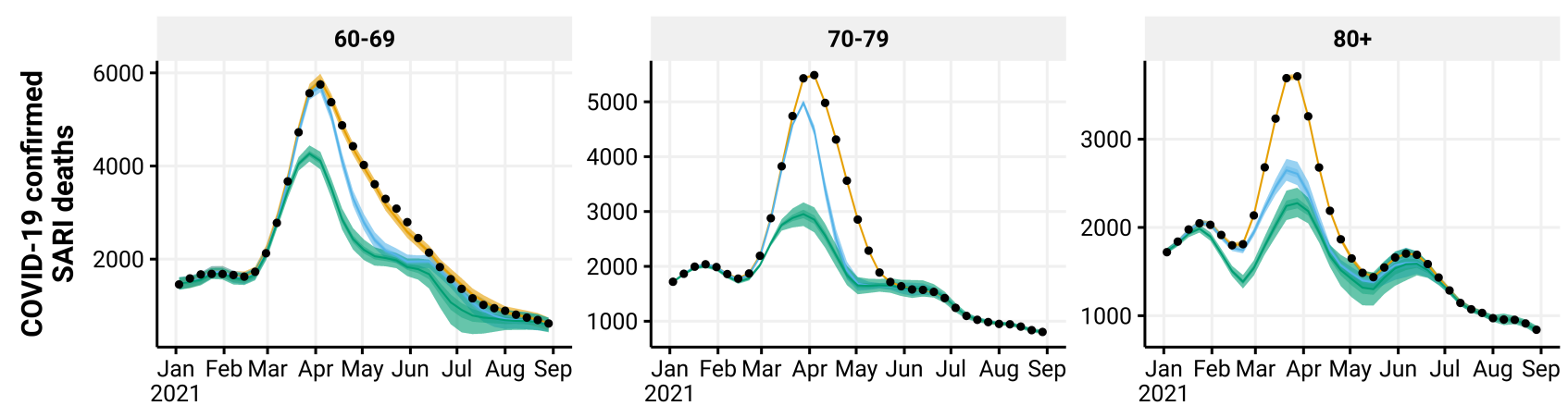

Epidemiological week of death

Vaccination • Realized • 4 weeks earlier • 8 weeks earlier

Figure 2: Estimated number of hospitalizations (top) and deaths (bottom) due to COVID-19 by epidemiological week with the realized (orange), 4 (blue) and 8 weeks earlier vaccination rollout, by age group (panels). The observed number of hospitalizations and deaths are given by the black points.

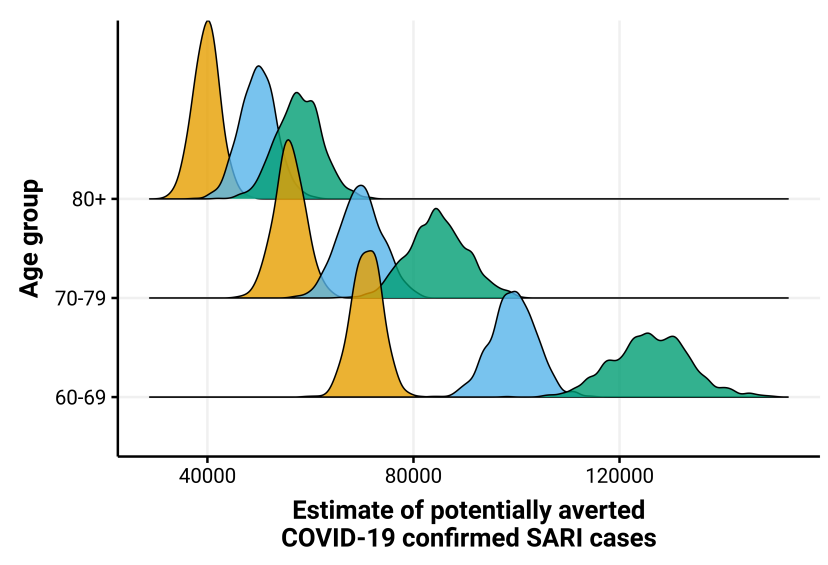

Vaccination $\square$ Realized $\square 4$ weeks earlier $\square$ 8 weeks earlier

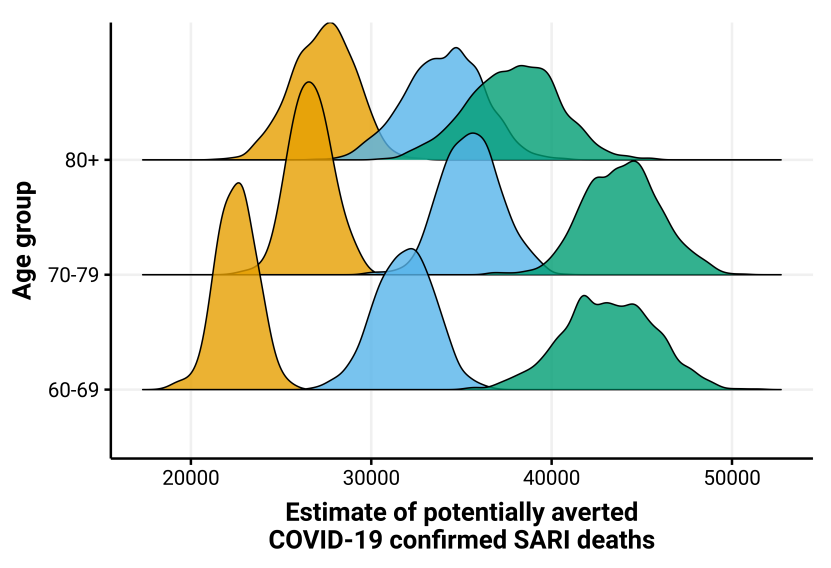

Vaccination $\square$ Realized $\square 4$ weeks earlier $\square 8$ weeks earlier

Figure 3: Posterior distribution of hospitalizations (left) and deaths (right) due to COVID-19 potentially averted by vaccination between January 1, 2021, and August 29, 2021, by age group, with the realized (orange), 4 (blue) and 8 weeks earlier (green) vaccination rollout.

to COVID-19, and other approximately 100 thousands individuals would not be hospitalized if the immunization started as soon it was approved in Brazil. If we consider the mean cost of US $\$ 12,000.00$ per admission in hospital [14], Brazil did not paid out more than 2 billion dollars as a direct effect of vaccination. Starting 8 weeks earlier it would mean saving other 1 billion dollars. We also estimate that more than 75 thousand lives were saved in the period 
medRxiv preprint doi: https://doi.org/10.1101/2021.12.24.21268384; this version posted December 27, 2021. The copyright holder for this preprint (which was not certified by peer review) is the author/funder, who has granted medRxiv a license to display the preprint in

It is made available under a CC-BY-ND 4.0 International license.

Table 1: Estimated reductions in hospitalizations/deaths by age group and vaccine rollout. $60+$ is the aggregate of the other age groups.

\begin{tabular}{|c|c|c|c|}
\hline Outcome & Age Group & Vaccine rollout & Estimated reduction $(95 \% \mathrm{CI})$ \\
\hline \multirow{12}{*}{ Hospitalizations } & \multirow{3}{*}{$60+$} & Realized & $166,780(157,198-176,309)$ \\
\hline & & 4 weeks earlier & $219,006(205,903-232,651)$ \\
\hline & & 8 weeks earlier & $268,614(248,858-289,034)$ \\
\hline & \multirow{3}{*}{$60-69$} & Realized & $70,987(65,238-76,641)$ \\
\hline & & 4 weeks earlier & $99,425(90,605-107,850)$ \\
\hline & & 8 weeks earlier & $126,102(111,585-141,016)$ \\
\hline & \multirow{3}{*}{$70-79$} & Realized & $55,957(50,158-61,945)$ \\
\hline & & 4 weeks earlier & $69,774(61,846-78,351)$ \\
\hline & & 8 weeks earlier & $84,721(74,065-96,134)$ \\
\hline & \multirow{3}{*}{$80+$} & Realized & $39,837(34,861-44,874)$ \\
\hline & & 4 weeks earlier & $49,806(43,109-56,685)$ \\
\hline & & 8 weeks earlier & $57,791(49,327-66,424)$ \\
\hline \multirow{12}{*}{ Deaths } & \multirow{3}{*}{$60+$} & Realized & $76,503(71,832-80,714)$ \\
\hline & & 4 weeks earlier & $101,416(95,079-107,091)$ \\
\hline & & 8 weeks earlier & $124,962(116,573-132,234)$ \\
\hline & \multirow{3}{*}{$60-69$} & Realized & $22,518(20,370-24,564)$ \\
\hline & & 4 weeks earlier & $31,849(28,648-34,863)$ \\
\hline & & 8 weeks earlier & $43,158(38,122-47,858)$ \\
\hline & \multirow{3}{*}{$70-79$} & Realized & $26,637(24,440-29,027)$ \\
\hline & & 4 weeks earlier & $35,518(32,511-38,783)$ \\
\hline & & 8 weeks earlier & $43,916(39,993-48,055)$ \\
\hline & \multirow{3}{*}{$80+$} & Realized & $27,348(23,830-30,440)$ \\
\hline & & 4 weeks earlier & $34,049(29,765-38,110)$ \\
\hline & & 8 weeks earlier & $37,888(32,962-42,515)$ \\
\hline
\end{tabular}

analysed, and additional 48 thousands lives could be saved if the Brazilian Government started the immunization 8 weeks earlier, i.e. at least $20 \%$ of the actual deaths in $60+$ y.o. individuals during the period analysed could be avoided. These numbers reflect only the direct protection of the vaccines, because our Bayesian model approach does not include a mechanistic model of disease transmission, that would require the use of SIR-like models [10]. Therefore, herd immunity by vaccines is not considered, and it is one of the most important effects of vaccines: protection of the community. This effect is expected to become more prominent when a large amount of individuals were immunized, although effects can be detected before the theoretical herd immunity threshold (based on the reproduction number) is reached if the epidemic is under control and especially when superspreaders are reached by the immunization [12, 13]. Moreover, Brazil is a large country with very different realized paces of immunization due to regional wealth (e.g. more poor states in the north and northeast regions), age distribution, and geographical difficulties (as the Amazon rain forest and large rivers) [2]. Differences among states and regions can be observed how earlier the orange curve (the scenario with vaccination) detaches from a scenario without vaccination, i.e., how earlier we observe the positive results of vaccination (see Figs in the SM). Therefore, a controlled epidemic in other states, especially the most populous ones, would have allowed the Federal government to increase the vaccination 
medRxiv preprint doi: https://doi.org/10.1101/2021.12.24.21268384; this version posted December 27, 2021. The copyright holder for this preprint (which was not certified by peer review) is the author/funder, who has granted medRxiv a license to display the preprint in

It is made available under a CC-BY-ND 4.0 International license .

rate, channel efforts and resources to the states under complicated situations. This effect can also be understood as an indirect effect of vaccination, and it is also not accomplished by the model in any hypothetical scenario.

During the period analysed, Brazil was hit by the emergence of the VOC Gamma, first detected in Manaus, capital of Amazonas state, in January. Later, all Brazilian states were seriously affected, with outrage of oxygen and hospital beds in the most complicated cases. Our scenario starting immunizations 2 months earlier presents a big gap in hospitalizations and deaths compared to the realized case, especially above 70 y.o.. When analysing the Amazonas state for any scenario, we do not detect an important difference if vaccination was started earlier (see SM - AM state). This can be due to two different reasons: (i) the Amazonas people is young, with a large concentration of individuals in the basal part of the pyramid age structure, surpassing the Brazilian age groups in ages below 25 y.o. [8]. Because in Brazil the vaccination obeyed a priority $[18,11]$ according to decreasing ages (the most important category), comorbidity, and working role, the young population of Amazonas state had a big delay related to the rest of country; (ii) the first samples of Gamma variant date on the beginning of December, 2020 and its emergence is estimated in November, 2020 [5, 21]. Starting vaccination in Brazil in 2020 was not a possible scenario because vaccines were not approved at that time [1]. Therefore even eight weeks of earlier vaccination would not have avoided the emergence of Gamma variant. Notwithstanding the vaccines would not prevent the emergence of a VOC in this region, if vaccination had started 8 weeks earlier, this scenario could avoid hospitalizations if a speed up of the vaccination in the region was carried due to the emergency. As a consequence, other states could have experienced a lower wave due to the Gamma variant. It is also interesting to highlight that in the earliest start possible scenario (eight weeks), the most populous states (São Paulo, Minas Gerais, Rio de Janeiro and Bahia states) show a clear advantage during the beginning of the Gamma wave, which can be observed when the the hypothetical curve detaches from both the realized and no vaccination curves (see SM). Finally, we highlight that non pharmacological interventions (NPI) would still be necessary to avoid the catastrophic situation Brazil faced from January to August, 2021.

In most of the Brazilian states, adults below 60 y.o. started their immunization in June, 2021 [17]. In this sense, the herd immunity effects take an important role since then. About $88.9 \%$ of the adult Brazilian population (18+ y.o.) concluded their full vaccination in December, 2021 [17]. In this case, we believe further analysis accounting the positive effects in the Brazilian population as a whole for the hypothetical scenarios presented here require a model such as ours combined with a SIR-like compartmental model. Brazil has a high death number in pediatric mortality due to COVID-19. For the 5-11 y.o. group the COVID-19 was the cause of 3302 and 3317 hospitalizations in 2020 and 2021 (until November 29, 2021), respectively [19], whereas looking at the 5-11 y.o. group 156 and 142 deaths occurred in 2020 and 2021 (until November 29, 2021), respectively, as a consequence of COVID-19 [19]. Additionally, deaths due to SARI consequences were 450 and 292 in 2020 and 2021 (until November 29, 2021), respectively [19]. In order to compare the magnitude of these numbers, we can look at the main mortality cause of children in the 5-9 y.o. group: disregarding external causes (such as violence), nervous system diseases and neoplasms, the greatest cause of mortality between 2015 and 2019 was the sum of all respiratory system diseases, which in average caused 283 deaths [16]. These numbers put an evident importance of the role COVID-19 is playing in children mortality. The BNT162b2 pediatric vaccine was approved by the Brazilian Health Regulatory Agency (ANVISA) in December 16, 2021 [15] and the starting date is not yet set in the National Immunization Program (PNI). Unfortunately, using only the present model approach we can not make forecasts of how many hospitalizations and deaths among children could be avoided if immunization had started as soon as it was approved in the country. A combined approach between this and a SIR-like model would allow us to estimate the indirect effects of adults 
medRxiv preprint doi: https://doi.org/10.1101/2021.12.24.21268384; this version posted December 27, 2021. The copyright holder for this preprint (which was not certified by peer review) is the author/funder, who has granted medRxiv a license to display the preprint in

It is made available under a CC-BY-ND 4.0 International license .

vaccination on children and also to understand how many children lives could be saved directly since the vaccine approval. Based on the present model results, in which we observe the direct effect of saved lives comparing to a scenario with no vaccination, we can say, in advance, that postponing children vaccination is allowing avoidable suffering and deaths.

\section{Acknowledgements}

All authors thank the members of Observatório COVID-19 BR for their insightful discussion of the results of this work. Specially, we would like to thank Verônica Coelho, Maria Amélia Veras, Brigina Kemp, Maria Rita Donalísio, Lorena Barberia, Flávia Ferrari, José Cassio Moraes and Guilherme Werneck for their comments.

The authors also thank the research funding agencies: the Coordenação de Aperfeiçoamento de Pessoal de Nível Superior - Brazil (Finance Code 001 to FMDM and LSF), Conselho Nacional de Desenvolvimento Científico e Tecnológico - Brazil (grant number: 315854/2020-0 to MEB, 141698/2018-7 to RLPS, 313055/2020-3 to PIP, 311832/2017-2 to RAK), Fundação de Amparo à Pesquisa do Estado de São Paulo - Brazil (contract number: 2016/01343-7 to RAK), Fundação de Amparo à Pesquisa do Estado do Rio de Janeiro - Brazil (grant number: E-26/201.277/2021 to LSB) and Inova Fiocruz/Fundação Oswaldo Cruz - Brazil to LSB. The funding agencies had no role in the conceptualization of the study.

\section{Data Availability Statement}

All data and code used in this work is pubicly available at https://github.com/covid19br/ bayes-vacina-paper.

\section{CRediT Author Statement}

Conceptualization - LSF, LSB, MEB and RLPS. Methodology - LSF, LSB and PIP. Software - LSF. Validation - PIP. Formal Analysis - LSF. Investigation - LSF. Data Curation - MEB and RLPS. Writing - Original Draft - LSF, FMDM and RLPS. Writing - Review \& Editing - All authors. Visualization - MFCG and LSF.

\section{References}

[1] Governo do Brasil. Anvisa aprova por unanimidade uso emergencial das vacinas. 2021. URL: https://www.gov.br/pt-br/noticias/saude-e-vigilancia-sanitaria/2021/ 01 / anvisa-aprova-por-unanimidade-uso-emergencial-das-vacinas (visited on $12 / 22 / 2021)$.

[2] Marcia C. Castro et al. "Spatiotemporal pattern of COVID-19 spread in Brazil". In: Science 372.6544 (May 2021), pp. 821-826. DOI: 10.1126/science.abh1558. URL: https: //doi.org/10.1126/science.abh1558.

[3] Renato Mendes Coutinho et al. "Model-based estimation of transmissibility and reinfection of SARS-CoV-2 P.1 variant". In: Communications Medicine 1 (2021), p. 48. DOI: 10.1038/s43856-021-00048-6. URL: https://doi.org/10.1038/s43856-021-000486.

[4] Carla Magda Allan S. Domingues and Wanderson Kleber de Oliveira. "Uptake of pandemic influenza (H1N1)-2009 vaccines in Brazil, 2010". In: Vaccine 30.32 (July 2012), pp. 4744-4751. DOI: 10.1016/j.vaccine.2012.05.007. URL: https ://doi .org/10. 1016/j.vaccine.2012.05.007. 
medRxiv preprint doi: https://doi.org/10.1101/2021.12.24.21268384; this version posted December 27, 2021. The copyright holder for this preprint (which was not certified by peer review) is the author/funder, who has granted medRxiv a license to display the preprint in

It is made available under a CC-BY-ND 4.0 International license .

[5] Nuno R. Faria et al. "Genomics and epidemiology of the P.1 SARS-CoV-2 lineage in Manaus, Brazil". In: Science 372.6544 (May 2021), pp. 815-821. DOI: 10.1126/science. abh2644. URL: https://doi.org/10.1126/science.abh2644.

[6] Elize Massard da Fonseca, Kenneth C. Shadlen, and Francisco I. Bastos. "The politics of COVID-19 vaccination in middle-income countries: Lessons from Brazil". In: Social Science \& Medicine 281 (July 2021), p. 114093. DOI: 10.1016/j . socscimed. 2021. 114093. URL: https://doi.org/10.1016/j.socscimed.2021.114093.

[7] Fundação Oswaldo Cruz. VIGILÂNCIA GENÔMICA DO SARS-CoV-2 NO BRASIL. 2021. URL: http://www.genomahcov.fiocruz.br/dashboard/ (visited on 12/24/2021).

[8] Instituto Brasileiro de Geografia e Estatística. Projeção da população brasileira para 2020. 2021. URL: https : / / www . ibge . gov . br / apps / populacao / projecao / index . html (visited on 12/19/2021).

[9] Rafael Izbicki et al. "How many hospitalizations has the COVID-19 vaccination already prevented in São Paulo?" In: Clinics 76 (2021). DOI: 10.6061/clinics/2021/e3250. URL: https://doi.org/10.6061/clinics/2021/e3250.

[10] Matt J. Keeling and Pejman Rohani. Modeling Infectious Diseases in Humans and Animals. English. Hardcover. Princeton University Press, Oct. 2007, p. 384. ISBN: 9780691116174. URL: https : / / lead . to / amazon / com / ?op = bt \& la = en \& cu =usd \& key = 0691116172.

[11] Raquel Martins Lana et al. "Identificação de grupos prioritários para a vacinação contra COVID-19 no Brasil". In: Cadernos de Saúde Pública 37.10 (2021). DOI: 10.1590/0102311x00049821. URL: https://doi.org/10.1590/0102-311x00049821.

[12] J. O. Lloyd-Smith et al. "Superspreading and the effect of individual variation on disease emergence". In: Nature 438.7066 (Nov. 2005), pp. 355-359. DOI: 10.1038/nature04153. URL: https://doi .org/10.1038/nature04153.

[13] Jan Medlock and Alison P. Galvani. "Optimizing Influenza Vaccine Distribution". In: Science 325.5948 (Sept. 2009), pp. 1705-1708. DOI: 10.1126/science.1175570. URL: https://doi.org/10.1126/science.1175570.

[14] Anna Miethke-Morais et al. "Unraveling COVID-19-related hospital costs: The impact of clinical and demographic conditions". In: (Dec. 2020). DOI: 10.1101/2020 .12.24 . 20248633. URL: https://doi.org/10.1101/2020.12.24.20248633.

[15] Ministério da Saúde. Anvisa aprova vacina da Pfizer contra Covid para crianças de 5 a 11 anos. 2021. URL: https://www.gov. br/anvisa/pt-br/assuntos/noticiasanvisa/2021/anvisa-aprova-vacina-da-pfizer-contra-covid-para-criancasde-5-a-11-anos (visited on 12/16/2021).

[16] Ministério da Saúde. Banco de dados do Sistema Único de Saúde - DATASUS. Informações de Saúde, Sistema de Informações sobre Mortalidade. 2021. URL: http: // tabnet . datasus . gov . br / cgi / tabcgi . exe? sim / cnv / obt10uf . def (visited on $12 / 21 / 2021)$.

[17] Ministério da Saúde. Campanha Nacional de Vacinação contra Covid-19. 2021. URL: https : / / opendatasus . saude.gov . br/dataset/covid-19-vacinacao (visited on $11 / 15 / 2021)$.

[18] Ministério da Saúde. Plano Nacional de Operacionalização da Vacinação contra Covid19. 2021. URL: https : / / www . gov . br / saude/pt-br / coronavirus / publicacoes tecnicas/guias-e-planos/plano-nacional-de-vacinacao-covid-19 (visited on $12 / 22 / 2021)$. 
medRxiv preprint doi: https://doi.org/10.1101/2021.12.24.21268384; this version posted December 27, 2021. The copyright holder for this preprint (which was not certified by peer review) is the author/funder, who has granted medRxiv a license to display the preprint in

It is made available under a CC-BY-ND 4.0 International license.

[19] Ministério da Saúde. SRAG 2021 - Banco de Dados de Síndrome Respiratória Aguda Grave - incluindo dados da COVID-19. 2021. URL: https://opendatasus . saude.gov . br/dataset/bd-srag-2021 (visited on 10/18/2021).

[20] Felipe Naveca et al. "Phylogenetic relationship of SARS-CoV-2 sequences from Amazonas with emerging Brazilian variants harboring mutations E484K and N501Y in the Spike protein". In: Virological.org (2021). URL: https : //virological .org/t/phylogeneticrelationship - of - sars - cov - 2 - sequences - from - amazonas - with - emerging brazilian-variants - harboring - mutations - e484k - and - n501y - in - the - spikeprotein/585.

[21] Felipe Gomes Naveca et al. "COVID-19 in Amazonas, Brazil, was driven by the persistence of endemic lineages and P.1 emergence". In: Nature Medicine 27.7 (May 2021), pp. 12301238. DOI: $10.1038 /$ s41591-021-01378-7. URL: https://doi .org/10.1038/s41591021-01378-7.

[22] Flávia C. Pacheco et al. "Decrease in the coverage of measles-containing vaccines and the risk of reestablishing endemic transmission of measles in Brazil". In: International Journal of Infectious Diseases 82 (May 2019), pp. 51-53. DOI: 10.1016/j.ijid.2019.03.014. URL: https://doi.org/10.1016/j.ijid.2019.03.014.

[23] R Core Team. R: A Language and Environment for Statistical Computing. R Foundation for Statistical Computing. Vienna, Austria, 2021. URL: https://www.R-project.org/.

[24] Håvard Rue, Sara Martino, and Nicolas Chopin. "Approximate Bayesian inference for latent Gaussian models by using integrated nested Laplace approximations". In: Journal of the Royal Statistical Society: Series B (Statistical Methodology) 71.2 (Apr. 2009), pp. 319-392. DOI: 10.1111/j.1467-9868.2008.00700.x. URL: https://doi.org/10. $1111 / \mathrm{j} .1467-9868.2008 .00700 . \mathrm{x}$.

[25] Håvard Rue et al. "Bayesian Computing with INLA: A Review". In: Annual Review of Statistics and Its Application 4.1 (Mar. 2017), pp. 395-421. DOI: $10.1146 /$ annurevstatistics-060116-054045. URL: https://doi.org/10.1146/annurev-statistics060116-054045.

[26] Ester C Sabino et al. "Resurgence of COVID-19 in Manaus, Brazil, despite high seroprevalence". In: The Lancet 397.10273 (Feb. 2021), pp. 452-455. DOI: 10.1016/s01406736(21)00183-5. URL: https://doi .org/10.1016/s0140-6736(21)00183-5. 